\title{
The meaning and effect of HIV/AIDS stigma for people living with AIDS and nurses involved in their care in the North West Province, South Africa
}

\author{
Prof. Dr. M Greeff, D.Cur. (Psychiatric Nursing) \\ School of Nursing Science, Potchefstroom campus of the North-West University \\ R Phethu, M.Cur. (Nursing) \\ School of Nursing Science, Potchefstroom campus of the North-West University
}

Keywords:

HIV/AIDS, stigma, perceptions, types of stigma, dimensions of stigma
Correspondence address:

Prof M Greeff

School of Nursing Science

Potchefstroom campus of the North-West

University

Private Bag X6001

Potchefstroom

2520

Tel : (018) 299-1901

Fax : (018) 299-1827

E-mail : Minrie.Greeff@nwu.ac.za

\section{Abstract: Curationis 30(2): 12-23}

The five countries with the highest HIV prevalence rates in the world are situated in southern Africa, and South Africa, with an estimated 4,7 million people living with HIV (PLWA), has more cases of HIV/AIDS than any other country. AIDS stigma and discrimination continue to impact on those living with and affected by the HIV disease and their health-care providers, particularly in southern Africa, where the burden of AIDS is so significant. Stigma has become a major problem in the provision of care for PLWA in Africa. A five-year multinational African study on perceived AIDS stigma was undertaken. The North West Province in South Africa formed part of this study. The first phase focused on exploring and describing the meaning and effect of stigma for PLWA and nurses involved in their care. This article focuses on the data for the North West Province, South Africa. An exploratory descriptive qualitative research design was used. Through focus groups the critical incident method was applied to gain respondents' emic and etic views. The study was conducted in the Potchefstroom district and the Kayakulu area. Purposive voluntary sampling was utilised. The open coding technique was used for data analysis. Three types of stigma (received, internal and associated stigma) and several dimensions for each type of stigma were identified. Recommendations for interventions, a measuring scale and the formulation of a conceptual model were formulated.

\section{Background}

The number of people infected with HIV worldwide has increased exponentially from just a handful of cases in the early 1980s to about 40 million by the end of 2003 and more than 20 million people have already died of AIDS. Catastrophically, the extent of its impact turned out to be far worse than ever predicted (Abdool Karim \& Abdool Karim, 2005: 31). The five countries with the highest HIV prevalence rates in the world are situated in southern Africa, and South Africa, with an estimated 4,7 million people living with HIV (PLWA), has more cases of HIV/AIDS than any other country. The impact of the epidemic on all sectors of society, from urban industries to rural villages, is already being felt and will worsen as more people progress from asymptomatic HIV to AIDS (Connolly, Colvin, Shishana \& Stoker, 2004: 776). The life expectancy in 2004 was estimated to be 48.5 years for males and 52.7 years for females (Dorrington, Bradshaw, Johnson \& Budlender, 2004: 1).

Holzemer and Uys (2004: 166) mention that AIDS stigma and discrimination 
Table 1: Respondents by Groups, Gender and Age

\begin{tabular}{|l|l|l|l|l|l|l|l|}
\hline Groups & \# Groups & Men & Women & Total Sample & Mean Age & Urban Group & Rural Group \\
\hline PWLA & 4 & 9 & 9 & 18 & 39 & 2 & 2 \\
\hline Nurses & 4 & 1 & 15 & 16 & 49.75 & 2 & 2 \\
\hline Voluntecrs & 1 & 0 & 6 & 6 & 34 & 0 & 1 \\
\hline Totals & 9 & 10 & 30 & 40 & 40.92 & 4 & 5 \\
\hline
\end{tabular}

continue to impact on those living with and affected by the HIV disease and their health-care providers, particularly in southern Africa, where the burden of AIDS is so significant. Stigma is thus perceived as a major limiting factor in primary and secondary HIV/AIDS prevention and care. The meaning a person attributes to being stigmatized interferes with his/her readiness to seck voluntary testing and counselling and with the accessing of care and treatment, thus increasing suffering and shortening life. It affects not only HIV-positive people, but also the individuals, groups and community with which they are associated. Uys (2000: 160) states that many health-care workers have come to the conclusion that unless stigma is conquered, the illness will not be defeated. Stigma has thus become a major problem in the provision of care for PLWA in Africa (Greeff, Uys et al., 2006).

Due to the burden that HIV/AIDS places on people living in Africa, a five-year project entitled Perceived AIDS Stigma: A Multinational African study was undertaken. This project is a five-year collaborative project, linking members of five countries (South Africa, Malawi, Swaziland, Lesotho and Tanzania) where the research is being conducted, as well as the University of KwaZulu-Natal and the University of California as the coordinators of the project.

The aim of this project was to develop and validate two linguistically and culturally appropriate measures of perceived HIV/AIDS stigma appropriate for persons living with HIV/AIDS and nurse clinicians; to explore potential relationships, over time, among stigma, quality of health care and quality of life for people living with HIV/AIDS (PLWA), and among stigma, quality of work life and quality of life for nurse clinicians; and to utilise community-based participatory research methods to intervene at community level and to track the impact of the community-level events on the perceived stigma of nurses.

The focus of the first phase of this project was on exploring and describing the meaning and effect of stigma for PLWA and nurses involved in their care in the five aforementioned African countries through the description of incidents of stigma and how this had affected PLWA (Greeff, Uys, et al., 2006). The focus of this article is on the data of the North West Province, South Africa, from the first phase of the research conducted by the School of Nursing Science of the Potchefstroom campus of the North-West University as the South African collaborator.

\section{Problem statement}

Holzemer and Uys (2004: 165) state that while there is substantial anecdotal evidence of the impact of stigma on AIDS care, very little rigorous research has been conducted. De Bruyn (1999: 4-5) identified factors contributing to the HIV/ AIDS stigma, which include the fact that it is life-threatening, that people fear it, that it is associated with behaviour already stigmatised by many societies, e.g. drug abuse, and that people themselves are seen as responsible for contracting the disease. In South Africa the Siyam'kela research project (2003) was undertaken at more or less the same time as the first phase of this African study. Its aim was to explore HIV-related stigma and to develop HIV/AIDS stigma indicators which can be used to develop a tool to measure HIV/AIDS stigma mitigation programmes as well as formulate guidelines for developing a HIV/AIDS-supportive environment.

As mentioned under background, the African study was done to develop two validated instruments for PLWA and nurses involved in their care and to explore the stigma profile over time. How did PLWA and nurses involved in their care really experience stigma and how were they affected? It was felt that exploring and describing the meaning and effect of stigma as seen by PLWA and nurses involved in their care through described incidents of stigma would lead to a better understanding of this experience and lead to more congruent items in the instruments instead of using findings from other studies or other countries. The statement of Weiss and Ramakrishna (2001) that the nature of stigma may be different in different cultures with regard to what is stigmatised and how stigma is manifested supported our decision.

\section{Objective}

The purpose of this article is to focus on the South African data of the first phase of the research that involved exploring the meaning of stigma from the perspectives of PLWA and nurses involved in their care, and how this had affected PLWA.

\section{Literature review}

The literature review provides the theory of stigma and is a conceptual map for the findings. Although many definitions have been formulated to define stigma, the definitions of Goffman (1963:3) and the adjusted version of Alonzo and Reynolds (1995: 304) of Goffman were the definitions of choice for this research. Goffman (1963: 3) defined stigma as an attribute that is deeply discrediting within a particular social interaction. Alonzo and Reynolds (1995: 304) extended this definition to a powerful discrediting and tainting social label that radically changes the way individuals view themselves and are viewed as persons.

HIV/AIDS, especially in the context of poverty, results in considerable suffering. The issues surrounding prevention, transmission and mitigation is complex, but one very important 
concept sustaining the epidemic is stigma (Duffy, 2005: 13). Stigma, understood as a negative attribute, is mapped onto pcople, who in turn, by virtue of their differences, are understood to be negatively valued in society (Parker \& Aggleton, 2003: 14). Throughout much of the developing world, for example, bonds and allegiances to family, village, neighbourhood and community make it obvious that stigma and discrimination, when and where they appear, are social and cultural phenomena linked to the actions of whole groups of people, and not simply the consequences of individual behaviour (Parker \& Aggleton, 2003:17)

Because stigma has an impact on prevention and care, it is important to address it directly. Stigma-mitigating practices have not been well informed by theory and research. In a Malawian study it was noted that in a climate of stigma and silence, it was difficult for people living with HIV/AIDS to seek and access medical, psychosocial and spiritual scrvices (MANET, 2003: 1). In the Siyam'kela study, mention was made of $\mathrm{HIV}$ as an African disease, regarded with apathy in other communities, especially white communities (Siyam'kela, 2003: 13). The stigma, discrimination and resulting isolation means that people do not easily, if ever, disclose their diagnosis (Duffy, 2005: 16).

Stigma is also different when viewed from the inside, by those who are stigmatised, and from the outside, by those who stigmatise (Herek, Captanio et al., 2002: 372). The results of the Siyam'kela project were mainly categorised into stigma that could be felt (internal stigma), leading to an unwillingness to seek help and access resources, or enacted (external stigma), leading to discrimination on the basis of HIV status or association with someone who is living with HIV/AIDS. Indicators were divided into external stigma (avoidance, rejection, moral judgment, stigma by association, unwillingness to invest in PLWA, discrimination, abuse) and internal stigma (self-exclusion from services and opportunities, perception of self, social withdrawal, overcompensation, fear of disclosure). It was mentioned that past experiences of external stigma influence internal stigma as experienced by blame, rejection, intimidation, name-calling, exclusion and isolation (Siyam'kela, 2003: 5, 14-22). Weiss, Doongaji, Siddhartha et al., (1992) in their proposed conceptual model recognise that there is an insider's (emic) perspective and an outsider's (etic) perspective of the consequences of any illness studied. The emic view is rooted in local cultural concepts, reflecting the way people think of their world, themselves, health and health problems. The etic view relates more to professionally defined consequences, e.g. quality of health and quality of life.

De Bruyn (1999: 4-5) identified factors contributing to the HIV/AIDS stigma, which include the fact that it is lifethreatening, that people fear it, that it is associated with behaviours already stigmatised by many societies (e.g. drug abuse), and that people themselves are seen as responsible for contracting the disease. Herek, Mitnick, Burris, Chesney, Devine, Fullilove et al. (1998: 37) used the term 'AIDS-related stigma' to mean 'prejudice, discounting, discrediting, and discrimination that are directed at people perceived as having HIV or AIDS, and at individuals, groups and communities with which they are associated'. Berger, Ferrans and Lashley (2001: 518) developed an instrument to measure stigma perceived by people with HIV based on the literature of the time. Four factors emerged: personalised stigma, disclosure concerns, negative self-image and concern with public attitudes towards people with HIV.

Stigmatisation resulting in silence, secrecy and denial not only affects care and treatment, it has serious implications for prevention, which is critical in a disease with such a long subclinical phase (Duffy, 2005: 18). For nearly two decades, as countries over the world struggled to respond to the HIV/AIDS epidemic, issues of stigma, discrimination and denial have been poorly understood and often marginalised within national and international programmes and responses (Parker \& Aggleton, 2003:13). For a reduction in HIV/AIDS morbidity and mortality rates, there is a need to understand and act on contextual issues such as stigma with increased political and social commitment at local, national and international levels (Duffy, 2005: 13).

\section{Methodology}

The methodology describes the first phase of the five-year project as followed in the North West Province of South Africa. Two other articles have been published from the findings of the five countries, focusing on words and phrases people use to refer to HIV/AIDS and to PLWA (Uys, Chirwa et al., 2005) and the violation of human rights (Kohi, Makoae et al., 2006). A further article on the experiences of HIV/AIDS stigma by PLWA and nurses from five African countries is in the process of being published (Greeff, Uys et al., 2006). The latter article sets out the findings of the first phase about the perceived HIV/AIDS stigma as found in the five African countries. The discussion of methodology that follows is adapted from the article by Greeff, Uys et al. (2006).

\section{Research Design}

An exploratory, descriptive, qualitative research design (Mouton \& Marais, 1996: 45) was used to explore and describe the meaning and effect of HIV/AIDS stigma for PLWA and nurses involved in their care. Focus group discussions were held with respondents to capture an emic view of PLWA and an etic and emic view of nurses of stigma and discrimination (Weiss et al., 1992). The critical incident method was used. Respondents were asked to relate incidents which they themselves observed as well as those that they themselves experienced in the community and in families. Respondents were also asked to define their own understanding of what stigma and discrimination meant.

\section{Settings}

The study was conducted in the North West Province of South Africa, with Potchefstroom being the urban area and Kayakulu the rural area.

\section{Sample}

Purposive voluntary sampling was utilised to ensure that those participants who really had the best experience of stigma was included. A person to act as mediator was identified in the various areas. A letter to request their assistance was written, including an explanation of the aim of the research, as well as indicating the selection criteria for each group. For PLWA males and females were included separately, as were rural and urban groups; they had to be HIVpositive and be of various age groups, educational levels and durations since diagnosis. For nurses they had to be involved in the care of PLWA, vary in age, culture and religion, as well as work experience. 
Nine focus groups were conducted, which included a total of 40 respondents (see Table 1). Of the nine focus groups, four were conducted in urban settings and five in rural settings. In the urban setting, one focus group was held with each of the following groups: female PLWA, male PLWA, nurses involved in the care of PLWA and their nurse managers. In the rural setting one additional focus group was conducted with volunteers (the latter as they expressed a need to verbalise their views when they heard about the focus groups that were going to be held). The respondents were thus persons living with HIV/AIDS (45\%, $\mathrm{n}=18)$, nurses and nurse managers $(40 \%$, $\mathrm{n}=16)$, and volunteers $(15 \%, \mathrm{n}=6)$. The overall mean age of respondents was 40,92 years. Women constituted $50 \%$ of PLWA, 93,75\% of the nurses and 100\% of the volunteers.

\section{Data Collection}

Respondents were invited to a health clinic in both the urban and the rural settings, where focus group discussions were conducted. Respondents were reimbursed for transport and lunch was provided.

A brief demographic questionnaire was completed by all respondents. A focus group discussion guide was used during the focus groups. The broad questions were:

1. What words are used in your community to describe people who have HIV/AIDS?

Can you think of an incident that illustrates/shows how people in your community see or behave towards people with HIV/AIDS?

Probes were used to elicit further details of the incidents described: Circumstances leading to the event, what did people do, how did they respond to those people, how did those people's actions affect their behaviour? Focus group discussions were conducted in Afrikaans, English, Setswana, Sesotho and isiZulu so that respondents, including nurses, could be more comfortable expressing themselves in the local language. The co-researcher simultaneously communicated with respondents across these languages.

The focus group discussions were audio-recorded and translated into English by a transcriber during the transcribing process. The co-researcher once again listened to each tape to ensure that the translation was correct. The Nvivo ${ }^{1 \mathrm{M}}$ software was used to code demographic attributes (country, type of participant, gender) and themes.

After each focus group, field notes werc written reflecting observations, methodology and perceptions.

\section{Protection of Human Subjects}

The research protocol was approved by the NIH and the university's ethics committee, providing protection of human subjects. Permission to conduct the study was also obtained from the Department of Health of the North West Province, as well as from the Director of Health of the Potchefstroom district.

Respondents were provided with information about the background of the study, informed that participation was voluntary and that they could withdraw from participation at any time. Respondents were also assured of confidentiality of information obtained. Following this explanation, respondents each signed a written consent form.

\section{Data Analysis}

The textual data from the focus groups were analysed, using a qualitative data analysis package, NVivo 2.0. The transcripts were analysed by the researchers using the open coding technique of Tesch (in Creswell, 1994). Coding was done using sections of the text that were labelled by the coder as an incident. An incident was defined as 'a narrated event, including the circumstances, what happened, the actions taken and feelings of respondents, and then the results of the incidents. It could be as short as several sentences or as long as several paragraphs discussed'. Several free nodes (Nvivo 2.0) were identified, e.g. self-stigma, nurse stigma, other healthcare stigma, family stigma, community stigma, outcomes, disclosure, descriptions of PLWA, help-seeking behaviour, meaning of stigma, patterns of distress and other incidents.

Consensus discussions where held. The initial free nodes were developed into three broad categories of types of stigma, namely received stigma, internal stigma and associated stigma. Several subcategories which formed the dimensions of each of the types of stigma were further developed. During the analysis it was found that one incident could include several dimensions of stigma.

Initial definitions of the types of stigma and the various dimensions of stigma were developed, based on the verbal responses of the respondents. Discrepancies were discussed until unambiguous categories and explicit definitions were agreed upon.

\section{Trustworthiness}

Rigour was ensured in this rescarch using the model of Guba (in Krefting, 1991: 30) to assess the trustworthiness of the qualitative data. Truth value, applicability, consistency and neutrality were used as criteria to assess the value of the findings. See table 2 for an outline of how it was applied to this research.

\section{Results}

Three types of stigma were identified with nine dimensions of received stigma (neglecting, fearing contagion, avoiding, rejecting, labelling, pestering, negating, abusing and gossiping) and four dimensions for internal stigma (perceptions of self, social withdrawal, self-exclusion and fear of disclosure). Two dimensions were identified for associated stigma (spouse/children/ family and health-care workers). Two additional themes, not related to types of stigma, were identified through an endeavour to understand the context of stigma: results of stigma, and disclosure.

The results are discussed by first reflecting on the three types of stigma as it manifested in selected described incidents by respondents. The focus is on the incident as a whole and not the various dimensions. One or more of the dimensions may be present in an incident of stigmatisation. A discussion of the dimensions of the various types of stigma follows the discussion mentioned, using verbal accounts (passages) of the respondents. The latter is focused on a better understanding of each dimension. See table 3 for an exposition of the structure followed as well as an indication of the number of passages (verbal accounts) for each dimension.

\section{Types of stigma}

As indicated under the discussion of the analysis of the data three main categories for the types of stigma: received stigma, 


\begin{tabular}{|c|c|c|}
\hline $\begin{array}{l}\text { Criteria } \\
\text { Truth value }\end{array}$ & $\begin{array}{l}\text { Strategy } \\
\text { Credibility: } \\
\text { Triangulation } \\
\text { Peer examination } \\
\text { Prolonged engagement } \\
\text { Reflexive analysis }\end{array}$ & $\begin{array}{l}\text { Application } \\
\text { Focus groups were conducted by experienced researchers; field } \\
\text { notes were taken and the theory reviewed; a trial run of the } \\
\text { interview schedule was done. } \\
\text { An evaluation of the research proposal by peer reviewers and } \\
\text { the funding agent; the interview schedule was evaluated by } \\
\text { experts. } \\
\text { Researchers known in the community as part of service delivery; } \\
\text { a relationship of trust exists; an extended time was spent with } \\
\text { the respondents. } \\
\text { Two researchers were involved; field notes were written to } \\
\text { ensure that observations and experiences were captured }\end{array}$ \\
\hline Applicability & $\begin{array}{l}\text { Transferability: } \\
\text { Interview techniques } \\
\text { Comparison of sample to } \\
\text { demographic data } \\
\text { Dense description } \\
\text { Nominated sample }\end{array}$ & $\begin{array}{l}\text { Focus group techniques increased credibility through reframing, } \\
\text { repeating and expanding. } \\
\text { Selection criteria ensured that it would have been possible to } \\
\text { involve more respondents in the area. } \\
\text { Detailed information about the context, respondents and } \\
\text { methodology allows other researchers to transfer the findings. } \\
\text { Mediators in the community were used to identify the } \\
\text { respondents in the community. }\end{array}$ \\
\hline Consistency & $\begin{array}{l}\text { Dependability: } \\
\text { Code-recode } \\
\text { Dependability audit } \\
\text { Dense description of research } \\
\text { methods }\end{array}$ & $\begin{array}{l}\text { Data were analysed by both researchers; consensus } \\
\text { discussions were held to reach consensus about categories } \\
\text { and sub-categories } \\
\text { The verbatim capturing of the focus groups on audiotape and } \\
\text { field notes made auditing possible. } \\
\text { Detailed description of the methodology makes the study } \\
\text { repeatable }\end{array}$ \\
\hline Neutrality & $\begin{array}{l}\text { Confirmability: } \\
\text { Confirmability audit }\end{array}$ & $\begin{array}{l}\text { The initial identification of respondents was done by mediators } \\
\text { with no vested interest; transcriptions and fields notes can be } \\
\text { made available for auditing. }\end{array}$ \\
\hline
\end{tabular}

internal stigma and associated stigma emerged from the data.

\section{1) Received stigma}

The first type of stigma, received stigma, refers to stigmatising behaviour of neglecting, fearing contagion, avoiding, rejecting, labelling, pestering, negating, abusing and gossiping about persons living with HIV/AIDS as experienced or described by themselves or others (Greeff, Uys et al., 2006). It is similar to external or enacted stigma indicators described by the Siyam'kela research project (2003: 14), or it refers to the etic or outsider's view of Weiss et al. (1992: 819 830).

The total number of verbal responses for received stigma was 155 . The two dimensions of this type of stigma that reflected more verbal responses than the other dimensions are gossiping (36) and labelling (28). Negating reflected the least verbal responses from respondents (7).

Received stigma was evident from the following incidents, as described by nurses and a PLWA and quoted directly from transcripts of the focus groups: 
Table 3: Types and dimensions of HIV/AIDS stigma

\section{TYPES AND DIMENSIONS OF HIV/AIDS STIGMA}

\section{NUMBER OF PASSAGES}

TYPE: Received stigma (Etic view) $=155$ total passages

All types of stigma behaviour towards a person living with HIV/AIDS as experienced or described by themselves or others

\begin{tabular}{l|l}
\hline Dimensions & 14 \\
Neglecting & 16 \\
Fearing contagion & 16 \\
Avoiding & 14 \\
Rejecting & 28 \\
Labelling & 14 \\
Pestering & 7 \\
Negating & 36 \\
Abusing & 155 \\
Gossiping & \\
Total & 36 \\
\hline
\end{tabular}

TYPE: Internal stigma (Emic view) $=128$ passages

Thoughts and behaviours stemming from the person's own negative perceptions about himself/herself based on his/her HIV status

\section{Dimensions}

Perceptions of self

Social withdrawal

Self-exclusion

15

Fear of disclosure

Total

128

TYPE: Associated Stigma $=12$ passages

Incidents that describe stigma against people who work or associate with HIV/AIDS-affected people.

\begin{tabular}{|l|l}
\hline Dimensions & 12 \\
Family/spouse & \\
Health-care workers & 12 \\
Total & \\
\hline
\end{tabular}

Additional themes not directly related to stigma $=94$ passages

Results of stigma

Disclosure

Total

94

Incident 1 described by a nurse:

"There was a patient. Now this patient he was living with his brother and his girlfriend. So the girlfriend was afraid of this patient, that she will get HIV from the patient, not from her own boyfriend. So what they did do, is the segregated him. He slept in a small room and he was very ill. He could not care for himself There was just a small window and they cooked the food and the food was pushed in that window. So nobody was talking to him, even the brother too. If we don't go there on Friday, on
Monday we find the plates and the spoons and everything. So he has his own utensils and everything. The patient used to cry, he used to cry."

Incident 2 as described by a nurse:

"I sat at a meeting with people that were 
highly educated. And the chairman of this meeting told us that he asked his wife to get rid of the lady that worked in their home. He knew that she was HIV positive and now was working with the salads and things. Now she must get rid of her."

Incident 3 as described by a PLWA:

"It means to be distant from you... they' sit around there... because you are close to your friends... mavbe they find out that you are sick. Those people stait to change their attitude, always they want themselves far away from you...you end up alone, your friends doesn't come to you. But I don't know that they knew. But something is happening ...they just isolate you and say you disappointed them...they just assume."

\section{2) Internal stigma}

The second type, internal stigma described by Greeff, Uys et al. (2006), refers to thoughts and behaviours (perceptions of self, social withdrawal. self-exclusion and fear of disclosure) stemming from the person living with HIV's own negative perceptions about him-/herself based on his/her HIV status. It refers to the internal or felt stigma mentioned by the Siyam'kela research project (2003: 19) and the emic or insider's perspective of Weiss et al. (1992: 819830).

The total number of responses for internal stigma was 128 . The number of verbal responses about fear of disclosure (85) was considerably higher than the other three dimensions, with perceptions of self (8) being the lowest.

The following incidents serve to enhance understanding of internal stigma:

Incident 4 as described by a nurse:

"A person I appointed as a clerk, he got sick just a month after we employed him and he stayed with his mother. He got so sick.... when we spoke to him he never said that. He never disclosed, because he knew and the doctor at the clinic also knew. But I always feel that if somebody wants to tell me something, they'll do it in their own time. But the next thing we heard was that he committed suicide."

Incident 5 as described by a PLWA:

"Sometimes to break the silence is difficult...because you see as a person... as an individual... vou wanted some people to know about this in order to live a normal life... but the same people that you tell them the story...they just go around the corner and talk about vou. So sometimes I want to break the silence but I just think of the things they' used to say about a friend of mine...I just hear them... So it is the one thing that makes people to take time to think about this... When I go to...even at church sometimes I feel I want to talk to the minister about this but I think again...It is those things...I just want to break the silence..."

\section{3) Associated stigma}

The last and third type of stigma, associated stigma identified by Greeff, Uys et al. (2006) is defined as incidents that describe stigma against people who work (health care workers) or associate with HIV/AIDS-affected people (spouse) partner, children, family, friends). It is similar to associated stigma as described in the Siyam'kela research project (2003: 17), but was categorised as a theme on its own and not as a theme under external stigma in this research.

The total number of passages for associated stigma was 12 and only made reference to spouse/family and healthcare workers.

Associated stigma was expressed through the following incidents:

\section{* Against nurses:}

Incident 6 as described by a nurse:

"What happens is most of the time, when we (murses) go to a conmunity; people can see you there with a certain company, so we're thinking maybe they have formulated a connotation about nurses who work with HIV. Also with the Condor [referring to vehicle]. When they stop with the Condor outside, they relate that to HIV."

Incident 7 as described by a nurse:

"Well the other side that I also experience is that people cannot believe that I'm working with people, because it's their own fault. Why do I do all these things for the people (PLWA)?"

\footnotetext{
* Against the family/spouse:

Incident 8 as described by a PLWA:

"You get some parents when the child say they are infected, there is changes in the house, being scared of what people are going to say about them. That cause the child to kill themselves."
}

Incident 9 as described by a nurse:

"We had one person, the spouse died and everybody was assuming that it was HIVI AIDS. And this person got so thin and sickly and all kinds of funny, vou know, this person looked terrible to say the least. And people were speculating, you know' it was hearsay, they hear his wife was, so he must be and it wasn't like that at all. He was just a very, very sick person. He looked after his wife for ages. You could see it in his face. He knew what was going on. He knew what people were saying."

\section{Dimensions of the three types of stigma}

Each of the three types of stigma has its own dimensions (Greeff, Uys et al., 2006). The dimensions emerged from the data as sub-categories. Each dimension will be discussed in detail and be illustrated with quotations (derived from the passages) from the transcripts of the focus groups.

\section{Dimensions of received stigma}

Nine dimensions of received stigma were identified: neglecting, fearing contagion, avoiding, rejecting, labelling, pestering, negating, abusing and gossiping. The definitions of these dimensions originated from the verbal responses of the various respondents (PLWA and nurses involved in their care) in the focus groups and were achieved through consensus discussions amongst the researchers (Greeff, Uys et al., 2006). The discussion will reflect quotes from PLWA separately from quotes from nurses.

\section{- $\quad$ Neglecting (14 passages):}

Neglecting is seen as offering or giving less care than is expected in a situation (Greeff, Uys et al., 2006).

Some verbatim quotations from the focus groups follow to enhance understanding of the dimension of neglecting. The results indicate that health-care services were not offered to PLWA, or were of low quality. Physical care like washing of the sick PLWA was withheld and no or little nutrition provided.

As expressed by the PLWA:

"They we not treating me well. They did not care about me, even if I could request something to eat, perhaps craving for something to eat, truly speaking they did not treat me well."

"Even at his home, they never came, 
never attended anything."

As expressed by nurses:

"When she went to the clinic they chased her awav, they didn't look after her."

"So when I went there one of the patients was crying only' to find that the patient was neglected, there being the stinking even the patient was mixed up when I went there."

- Fearing contagion (16 passages): This dimension was defined as behaviour that shows a fear of close or direct contact with a PLWA or things (clothing) he/she has used (Greeff, Uys et al., 2006).

Fearing contagion was seen in behaviour such as not wanting to touch the PLWA, or using the same toilet or cooking utensils and bed linen than the PLWA. Persons were fearful of PLWA coughing in their presence. If PLWA were employed, people feared being contaminated should the PLWA prepare their food.

As expressed by PLWA:

"Sometimes people would say' they will not touch the clothes vou have on because you have AIDS. Even water. They would not drink water out of the cup I touched or used, because I have AIDS infection."

"What were they fearful of? That she will infect them, or people will laugh at them?"

As expressed by nurses:

Most of the quotations in this context are from nurses and health workers. In some cases they also showed their own fear of contagion.

"You see the person using a mug. I will take another mug to drink water."

"If we were sharing a bed then you start not to share a bed with him."

"So the girlfriend was afraid of this patient, that she will get the HIV from the patient, not from her own bovfriend. So what they did do is they segregated him. He slept in a small room and he was very ill, he could not care for himself. There was just a small windon' and they cooked the food and the food was pushed in the nindow. So nobody was talking to him, even the brother too. If we don't go there on Friday, on Monday we find the plates from Friday, Saturday. Sunday and Monday. So he had his ow'n utensils and evervthing."
- Avoiding (16 passages): This dimension was defined as the deliberate limiting of social contact with PLWA. Isolating, which was initially coded separately as a free code, was later included as part of this dimension (Greeff, Uys et al., 2006).

The need to make less social contact with PLWA became evident from persons not visiting the PLWA or inviting him/her to their homes. The PLWA saw a decrease in the numbers of their friendships and they also experienced physical isolation.

\section{As expressed by PLWA:}

"But now' what surprised me is that I disclosed to her, she is a murse, she is my. friend...up until today she has not made an effort to visit me. I am afraid to visit her."

"You find yourself without friends. Now" people are afraid of vou."

As expressed by nurses:

"This person w'as your friend, or someone who has alwavs been very close to vou, when people see that person. they start moving away from him, they do not want to associate with him. They do not invite him to functions anymore. If they are playing soccer they start 'looking' at him.'

"They segregated him. He slept in a small room..."

"The father just built an extension to the main house and told her to stay there, and her children."

"It was just a small window' and they pushed the food through the windon: So nobody was talking to him."

- $\quad$ Rejecting (14 passages): This dimension referred to behaviour that humiliates PLWA or breaks off relationships with them, that separates PLWA from groups and that isolates $P L W A$ (Greeff, Uys et al., 2006).

Mention was made of people not talking to PLWA, chasing them away or locking them up, or that they were told to leave their houses, and that employers were getting rid of them.

As expressed by PLWA:

"Friends. I wanted to know' where did they see me. Presently' I do not have friends. All my friends deserted me. I am all alone."

"When she ended up being sick, even at her home, especially her younger sister. chased her away, saving that she is sick and things like that."

"They hate you because they know the disease you re suffering firm."

As expressed by nurses:

"Finally they said they were going to leave her out and they were not going to take her anwhere."

"The one girl, she was sixteen vears old. she came to me and she said, they were chasing her anay from the clinics in town. If she goes there she has a rash, she's got headaches, and she has diarrhoea. When she went to this specific clinic they chased her away, they didn't want to look after her."

"When they went there the patient was saving they are chasing her away saying she is going to infect them."

"The lady' when her family rejected her had to go and stay with somebody else."

"He was lying on a little carpet in front of the door and actually the oupa did not want him there anymore, because he was costing him too much money at that stage."

'The one assistant nurse said: 'Sister here's one of your AIDS patients again.' I nearly died. I could have killed that noman."

- $\quad$ Labelling (28 passages): This dimension is defined as attaching an identifing or negative term or sign to a PLWA, linking cause of infection to behaviour of the PLWA or blaming PLWA for their behaviour. Initially blaming was coded separately but was later integrated into this dimension (Greeff, Uys et al., 2006).

The results indicated that labelling occurred in relation to various aspects, e.g. the way in which health services were provided, like labelling the car used by health-care workers or the person providing the care, name calling, linking the label to specific aspects and ascribing the need for care to the behaviour of PLWA.

\section{As expressed by PLWA:}

"Perhaps he poisoned me or bewitched me."

"I don't believe that even now he know's that he has infected me because currently he fools around so much. He is doing something...you know' I don't know:"

"But I stayed pointing fingers saying maybe it is this one, maybe that doctor, I don 't understand."

“...accepted it because I didn't know 
where I got it...Is it from her or from where because I used to have other women outside..."

As expressed by nurses:

"If someone comes from the counselling room they call it the AIDS room. It means there is something with him."

"She was very thin. As she passed they said this one goes with Nkosi Johnson [well-known AIDS victim]."

"...because maybe some of them have got an anger towards this disease, they will just say, well, but it is their own fault."

"Because now she was staying with the in-law's and they want to blame the opposite sex. Who came, I mean who became ill first?"

"I've heard them say... he had so many girlfriends..."

- $\quad$ Pestering (14 passages): This dimension refers to persistent questioning of PLWA about his/her behaviour and illness (Greeff, Uys et al., 2006).

These results reflect behaviour where a person(s) constantly refer(s) to the PLWA status or question(s) them about their status, referring to the symptoms and pressurising the PLWA to use health-care facilities.

As expressed by PLWA:

"They will want to know why did we come to the clinic. They are going to probe and search. They will not be satisfied until they know the reason why we came here."

"Now they keep on phoning, trying to find out why I am not coming. But he (the doctor) does not want to tell me. I knew I would actually disclose to them." "She even told me that I see your body you have lost weight... and all this time you knew that you are sick you were fine, but since you know and your girlfriend keeps telling you that, I can see you are losing weight."

As expressed by nurses:

"Yes, her granny who used to take care of her, every time when she reprimanded her she would say: By the way they say this thing has AIDS."

"The aunt was suspicious she said: 'What are you suffering from?' And she would say, 'TB'. The aunt would say: 'Why are you taking drugs? So it means there's something wrong with you and you are not going to...you must tell me the truth, whether you are positive or not.",

"Immediately if you can see somebody is losing weight, they immediately ask her."

- $\quad$ Negating (7 passages): This dimension is defined as denving PLWA access to services and opportunities based on the PLWA health status (Greeff, Uys et al., 2006).

Only nurse clinicians commented on this dimension. In negating they referred to not providing health-care services when needed or sending PLWA away when they requested these services.

As expressed by nurses:

"No use sending the patient to the hospital. He will die anyway."

"Because, this poor child, she was crying, because she was so ill and nobody wanted to help her."

"They didn't want to help her and chased her away."

"Send the patient away home, it's no use sending the patient to the hospital, he will die anyway."

"And when you transfer the patient, just like a mental health, the mental ill patient, when you transfer to hospital he will discharge immediately. He won't be admitted; he will not even see the patient, that something must be done for this particular patient."

- Abusing (10 passages): This refers to verbal or physical behaviour intended to harm the PLWA (Greeff, Uys et al., 2006).

Verbal abuse took place in the form of singing songs about the person, namecalling and humiliating the person through laughing at him/her. Physical abuse took the form of being beaten by the spouse, family or the community and being thrown out of the house.

\section{As expressed by PLWA:}

"They were sometimes not treated well by other people. They would compose a song and sing about them. They would like talk indirectly about them. As you would go past they would sing the song."

"His last word when we broke up he said I must know I am a danger in the community."

"Yes they will scream at me because I stay with my in-laws."

"...that you will hear a person saving that one has HIV, and causing such pain that this person can die...pain caused by words."

As expressed by nurses:

Nurses confirm the experiences of the PLWA suffering abuse by the family and community. Even a doctor is quoted in these illustrations of verbal abuse against the PLWA.

"She was badly beaten up by her own family, her children actually. And from time to time it still happens that somebody in her vicinity gets to know that she's a PLWA and she gets beaten up time and again because of that."

"The doctor was not calm with her. She said: Did they tell you you have AIDS? Did they tell you you are going to die? And she went all over again."

- $\quad$ Gossiping (36 passages): This dimension is defined as spreading rumours and talking inappropriately to others about PLWA and their illness, without permission, uncaring, and in public (Greeff, Uys et al., 2006).

Gossiping occurred among people talking about the PLWA. This took place either amongst friends, in the community or at work. Quite often the gossip was based on assumptions.

As expressed by the PLWA:

"They say they go about talking about our illness."

"The spouse died and everybody was assuming that it was HIV/AIDS."

"As the person got thin people were speculating. You know, it was hearsay."

"You find people talking about you in the streets. You are not even certain who is talking. But you will know that they are talking about you."

"The next thing you hear the children saying that man has AIDS, my father said so."

As expressed by nurses:

Nurses confirmed this dimension, namely gossiping. People either talk indirectly in front of PLWA or more openly when they are not present.

"This person got so thin and sickly and all kinds of funny, you know, this person looked terrible to say the least. And people were speculating, you know it was hearsay, they hear his wife was, so he must be and it wasn't like that at all." "So what I learned, when they are seated during the mourning period before the funeral, they will start discussing openly, especially these old ladies - I've heard 
that he was very sick, he started having sores, he had swollen and he had so many girlfriends..."

"The community itself is very... They know before I know. They just look at the picture. They come and tell you. They watched that somebody and they think that somebody is sick."

\section{Dimensions of internal stigma}

Four dimensions of internal stigma were identified: perceptions of self, social withdrawal, self-exclusion and fear of disclosure (Greeff, Uys et al., 2006).

\section{- $\quad$ Perceptions of self (8}

passages): This dimension was defined as the negative evaluation of oneself based on one's HIV-positive status (Greeff, Uys et al., 2006).

The comments were of a self-blaming nature and negative. More PLWA than nurses expressed themselves verbally on this dimension.

As expressed by PLWA:

"I wasted my time and also hurt my father because I am sick. I am even afraid to tell my father that we broke up."

"My worry was why I have become thin so much. Because even the people see that. "

"After the child died, that stress came back...I pictured her, I thought, I am coming...I am going to follow her, I am going to die, such things."

As expressed by nurses:

"It is only now that she regrets going around with a lot of boyfriends and say they infected her. She does not even want the very boyfriend, she chases him away. She just does not want to lead that kind of life she wants to stay at home."

\section{- Social withdrawal}

passages): This refers to persons withdrawing from sexual and/or loving relationships to protect themselves from discrimination (Greeff, Uys et al., 2006).

The results indicated isolation from the community and a decrease in contact with people, even suicide.

\section{As expressed by PLWA:}

"You walk out through the gate then you decide let me go back. Hey. They will talk a lot, it is better for you to stay at home."

"I am even afraid to visit her."
"I will never talk to her again as long as I live."

As expressed by nurses:

"She would stay in the house and not go outside."

"She did not want us to touch or play with the baby."

"She does not want to communicate with anyone in the family."

"Then she is forever cross with people at home, even if you want to talk to her. She just says they must get out of her life. She does not even want to go to the clinic."

"But the next thing we heard was that he committed suicide. And he committed suicide in his room in his mother's house."

\section{- $\quad$ Self-exclusion (15 passages):}

This dimension is defined as the process by which a person decides not to use services due to being $H I V$-positive and fearing discrimination (Greeff, Uys et al., 2006).

The comments were mainly made by nurses and revolved around the decision by PLWA not to do anything or go to health-care facilities. Self-exclusion also took the form of suicide.

As expressed by PLWA:

"Yes she became stressed... she slept and slept until she ended up dead."

"So I told myself that it is useless to go to many places, and exposing myself among people."

"I had a problem at home. So okay I even thought of committing suicide, because...the doctor...because people do not treat me well."

As expressed by nurses:

"She was very downhearted and she didn't want to go back to that place."

"It's just that some patients when they come back from hospital they always say they will never go back to the hospital, they are beaten up, such things."

"Even for today some patients they walk out because they knew when people see them with us they are positive. So we have to convince them that no one will see that this is high blood patients."

- Fear of disclosure (85 passages): This refers to all behaviour related to revealing the HIV status of the person (Greeff, Uys et al., 2006).

The results reflect that PLWA fear rejection and loss of opportunities or relationships. They want to keep their status a secret and limit telling people.

As expressed by PLWA:

"If I have to tell my children it's a problem, with my partner I am just going to think that I am going to infect him. Who do I tell? The children are forever going to be disturbed, thinking about the fact that their mother is HIV positive. It means we are already orphans. Can you see we are going to make them live in fear?"

"They do not know what my problem is."

"I was only diagnosed last year. I have not told them at home. I want to settle first, then I will tell them."

"I am afraid that maybe as they come to my place they will soon hear something. I know what kind of people they are."

"When I go to...even church sometimes I feel I want to talk to the minister...I just want to break the silence."

As expressed by nurses:

"She kept it a secret. She even refused to tell her mother at home."

"And nobody...they also hid him away and did not want to open, but at the end she told."

"They didn't tell, they have a denial."

"He is afraid at how he will be treated. He is afraid because people will actually confirm and say that he is supposed to be sick he has been 'this way and that way'."

\section{Dimensions of associated stigma}

The dimensions of associated stigma that emerged from the data were on spouse/ children/family and health-care workers. The number of passages was not coded separately and totalled 12 .

\section{- $\quad$ Spouse/children/family: This} refers to incidents directed at the spouse, children or family of a person living with HIV/AIDS (Greeff, Uys et al., 2006).

The results indicated that the spouse, children or family became targets of stigmatisation as soon as the diagnosis became known.

The following quotes from $P L W A$ and nurses illustrate the findings:

"But the mother afterwards said that nobody visits her anymore after his death."

"You are not going to live happily. As they go past our homes they talk 
indirectly. They even say bad things to our children. They say your mother or father has this disease. The child starts to have problems."

"It's that when thev start with people involved with the person that died."

- Health-care workers: This refers to incidents directed at healthcare workers who care for people living with HIV/AIDS (Grceff, Uys ct al., 2006).

The results show that it is implied that something must be wrong with the nurses themselves who work with PLWA, or else they would not be prepared to work with these people.

The following quotes from PLWA and nurses illustrate the findings:

"They talk about her as the AIDS nurse and horrible things they have mentioned and this really got to her. Very badly."

"The patients said people sav sisters will only work with AIDS patients if they have AIDS themselves."

"My, colleagues, you know, they used to speak about 'your AIDS kids'. You know. in a negative way."

"People that don't understand why are there such a lot of money for HIV. Why do you work with them, because it is their own fault. And aren't you afraid to also get it? And how can you work with them? How can vou touch them?"

\section{Additional themes not directly related to stigma}

Two additional themes, not related to the types or dimensions of stigma, were identified: Results of stigma; and disclosure.

94 verbal responses in total related to these themes, 18 regarding results of stigma and 76 regarding disclosure. Because of the significance of the latter, this theme will be covered in detail in an article on "Disclosure of HIV status: Experiences and perceptions of persons living with HIV/AIDS and nurses involved in their care in five African countries" (Greeff, Phetlhu et al., 2006).

- Results of stigma (18 passages): This theme refers to the outcomes of stigma and can be described in many ways. Some measurable outcomes, however, are quality of life, quality of work life, access to health care and health behaviour (Greeff, Uys et al., $2006)$.
The outcomes of incidents resulted in PLWA either receiving health care or starting to utilise relevant health-care services. There were specific personal outcomes that had either positive or negative effects. Many of the results of stigma were focused on the outcomes of the illness. Education was also an important result.

The following quotes from PLWA illustrate the findings:

"The sister came and started me with food parcels."

"I had a problem at home. So okay, I even thought of committing suicide."

"Oh I am so pitying my poor wife. The wav I treated her. I used to beat her and now she is the one who is cleaning me up."

"The nurse warned her that she should never do that again..."

The following quotes from nurses illustrate the findings:

"Ifilled in the form with the mother and they were given food parcels and also this booster porridge."

"And when I stand in front of the door. I just asked the lady inside, hmm, 'we are fiom the health department', offering help. She looked at me and then said, 'yes please come in'."

"Patient went back to the clinic and they sorted things out."

"And I took her to clinic."

\section{- Disclosure (94 passages): This} refers to statements relating to disclosure or fears of disclosure of $\mathrm{HIV}$ status (Greeff, Uys et al., 2006). 94 passages were coded, indicating that this is a significant dimension of the stigma experience of PLWA.

The results focused on the conflict experienced by PLWA about whether to disclose or not, the choice of when and to whom to disclose, to disclose if there are benefits from the disclosure, e.g. ATR, and disclosure by health-care workers, which sometimes happened without the consent of the PLWA

The following quotes from PLWA illustrate the findings:

"I became sick and finally had to decide to go to the clinic. After I heard, I said I am not going to make this a secret, this is everybody's disease."

"My' people at home all know. I have not been treated badly."

"I have not told them at home. I want to settle first then I will tell them."

"It will take ahout two to three years to be able to accept and talk freely."

"I had a problem as how to tell them at home. Though I told them now only last month."

"Yes. At work I told them. I even told the manager."

"The doctor is not supposed to discuss my illness with someone. Why is he not talking to me first or why is he not telling him in my presence?"

The following quotes from nurses illustrate the findings:

"She said she is HIV positive and she wants milk for the baby."

"They have all reported and four of them disclosed to the family."

\section{Conclusion}

The experience of stigma is painful and difficult for PLWA. Spouses, children and family are often stigmatized through association, as are the nurses involved in their care. The experience of stigma is complex, with several types and dimensions of stigma that emerged from the data. The process of stigmatisation and discrimination has a tremendous effect on the person's quality of life, quality of work life and the utilisation of health-care services

\section{Recommendations}

- Interventions should be planned and implemented to alleviate the impact of stigma on all the various aspects of PLWA's lives. Attention must be given to the types as well as all the dimensions of stigma. It could be meaningful to develop and validate an instrument to measure the stigma experiences of both PLWA and nurses, including all the types and dimensions of stigma identified in this research.

- The findings of this rescarch should be developed into a conceptual model of HIV/AIDS stigma.

This project is supported by $\mathrm{R} 0 \mathrm{I}$ TW06395 Fogarty International Center, National Institutes of Health. This study was partially supported by the Health Resources and scrvices Administration's Global HIV/AIDS Program, U.S. Government (PI: I lolzemer, Co-PI: Uys) 


\section{Bibliography}

ABDOOL KARIM, SS \& ABDOOL KARIM, Q 2005: HIV/AIDS in South Africa. Cape Town: Cambridge University Press.

ALONZO, A \& REYNOLDS, N 1995: Stigma, HIV and AIDS: An exploration and elaboration of a stigma trajectory. Social Science and Medicine, 41(3): 303 315.

BERGER, BE; FERRANS, CE \& LASHLEY, FR 2001: Measuring stigma in people with HIV: Psychometric assessment of the HIV stigma scale. Research in Nursing \& Health, 24(6): 518 -529 .

CONNOLLY, C; COLVIN, M; SHISHANA, O \& STOKER, D 2004: Epidemiology of HIV in South Africa results of a national, community-based survey. South African Medical Journal, 94(9): 776 - 781.

CRESSWELL, JW 1994: Research design: Qualitative and quantitative approaches. London: Sage.

DE BRUYN, M 1999: Intersecting health risks: Adolescent unwanted pregnancy, unsafe abortion, and AIDS. Initiatives in Reproductive Health Policy, 3(1): 4 - 5.

DORRINGTON, R; BRADSHAW, D; JOHNSON, L \& BUDLENDER, D 2004: The demographic impact of HIV/AIDS in South Africa. National indicators for 2004. Cape Town: Centre for Actuarial Research, South African Medical Research Council and Actuarial Society of South Africa.

DUFFY, L 2005: Suffering, shame, and silence: The stigma of HIV/AIDS. Journal of the Association of Nurses in AIDS Care, 16(1): 13-20.

GOFFMAN, E 1963: Stigma: Notes on the management of spoiled identity. Englewood Cliffs, N.J.: Prentice-Hall.

GREEFF, M; UYS, LR; HOLZEMER, WL; MAKOAE, LN; DLAMINI, P; KOHI, TW; CHIRWA, ML; NAIDOO,J \& PHETLHU, R 2006: Experiences of HIV/AIDS stigma of PLWA from five African countries (Awaiting publication in African Journal of AIDS Research.)
NAIDOO, JR; KOHI, TW; UYS, LR \& CHIRWA, ML 2006: Disclosure of HIV status: Experiences and perceptions of persons living with HIV/AIDS and nurses involved in their care in five African countries (Accepted for publication in Qualitative Health Research.)

HEREK, GM; CAPTANIO, JP \& WIDAMAN, KF 2002: HIV-related stigma and knowledge in the United States: prevalence and trends, 1991-1999. American Journal of Public Health, 92(3): $371-377$.

HEREK, GM; MITNICK, L; BURRIS,S; CHESNEY,M;DEVINE,P; FULLILOVE, MT; FULLILOVE, R; GUNTHER, HC; LEVI, J; MICHAELS, S; NOVICK, A; PRYOR, J; SNYDER, M \& SWEENEY, T 1998: Workshop report: AIDS and stigma: A conceptual framework and research agenda. AIDS \& Public Policy Journal, 13(1): 36 - 47.

HOLZEMER, WL \& UYS, LR 2004: Managing AIDS stigma. Journal of Social Aspects of HIV/AIDS, 1(3) November 2004: 165 - 174.

KOHI,TW; MAKOAE, L; CHIRWA,M; HOLZEMER, WL; PHETLHU,DR;UYS, L; NAIDOO, J; DLAMINI, PS \& GREEFF, $M$ 2006: HIV and AIDS violates human rights in five African countries. Nursing Ethics, 13(4): 404 - 415.

KREFTING, L. 1991 : Rigor in qualitative research: The assessment of trustworthiness. American Journal of Occupational Therapy, 45(30) March 1991:214-222.

MANET 2003: Voices for equality and dignity. Research report, 18 July 2003, Lilongwe, Malawi.

MOUTON, J \& MARAIS, DC 1996: Basic concepts in the methodology of social sciences. Pretoria: HSRC Publishers.

PARKER, R \& AGGLETON, P 2003: HIV and AIDS-related stigma and discrimination: a conceptual framework and implications for action. Social Science \& Medicine, 57: 13-24.

SIYAM'KELA 2003: Research report on the fieldwork leading to the development of HIV/AIDS stigma indicators and guidelines. December 2003.
UYS, LR 2000: Confidentiality and HIV/ AIDS in South Africa. Nursing Ethics, 7(2): $158-166$.

UYS, LR; CHIRWA, M; DLAMINI, P; GREEFF, M; KOHI, T; HOLZEMER, WL; MAKOAE, L; NAIDOO, JR \& PHETLHU, R 2005: Eating plastic, winning the lotto, joining the WWW... Descriptions of HIV/AIDS in Africa. Journal of Nurses in AIDS Care, 16(3) June 2005:11-21.

WEISS, MG; DOONGAJI，DR; SIDDHARTHA，S; WYPIJ，D; PATHARE, S; BHATAWDEKAR, M; BHAVE, A; SHETH, A \&FERNANDES, R 1992: The Explanatory Model Interview Catalogue (EMIC) contribution to cross-cultural research methods from a study of leprosy and mental health. British Journal of Psychiatry, 160: 819 830.

WEISS, MG \& RAMAKRISHNA, J 2001: Stigma interventions and research for international health. Retrieved 21 February 2003, from http// :www.stigmaconference.nih.gov 